\title{
The Impact of HIV Spending on Health Outcomes in Thailand
}

\section{Shaheda Viriyathorn*, Saranya Sachdev, Yaowaluk Wanwong, Walaiporn Patcharanarumol, Viroj Tangcharoensathien}

International Health Policy Program (IHPP), Ministry of Public Health, Nonthaburi, Thailand

Email: *shaheda@ihpp.thaigov.net

How to cite this paper: Viriyathorn, S., Sachdev, S., Wanwong, Y., Patcharanarumol, W. and Tangcharoensathien, V. (2021) The Impact of HIV Spending on Health Outcomes in Thailand. World Journal of AIDS, 11, 85100

https://doi.org/10.4236/wja.2021.113008

Received: June 5, 2021

Accepted: August 24, 2021

Published: August 27, 2021

Copyright $\odot 2021$ by author(s) and Scientific Research Publishing Inc. This work is licensed under the Creative Commons Attribution International License (CC BY 4.0).

http://creativecommons.org/licenses/by/4.0/

\begin{abstract}
Background: The Sustainable Development Goals commitment to Ending HIV/ AIDS by 2030 requires sustained adequate investment. This study sought to examine the association between HIV/AIDS spending and outcomes in Thailand between 2008 and 2019. Methods: A quantitative secondary data analysis with time-series was conducted using a retrospective dataset of HIV spending and some selected outcomes including the number of people living with HIV (PLHIV), incidence and prevalence of HIV/AIDS, the prevention of mother-to-child transmission (PMTCT) and AIDS-related deaths. Data were obtained from a diverse set of sources. Descriptive statistics and univariate regression model were used to analyze HIV expenditure and outcomes. Results: HIV spending per PLHIV rose by two folds from $\$ 347$ in 2008 to more than $\$ 600$ in 2019, mostly financed by domestic sources. This increase of domestic resources per PLHIV was significantly associated with better HIV-related outcomes especially in the reduction of PLHIV and AIDS-related deaths through increased number of people receiving antiretroviral therapy (ART). However, the spending per PLHIV varied across the three public health insurance schemes. Comparison of HIV expenditure and health outcomes across uppermiddle-income countries shows Thailand is not highly ranked in terms of spending efficiency despite having made good progress. Conclusion: Domestic financing for HIV programs is indispensable for achieving the goal of ending AIDS. Despite significant improvement in HIV-related outcomes, challenges remain in achieving the 90-90-90 goal. The redesigning of payment methods should be considered to increase the efficiency of HIV financing. Other factors related to strengthening the health system should not be overlooked.
\end{abstract}

\section{Keywords}

HIV Spending, Healthcare Financing, HIV Infections, HIV Outcome 
Assessment, People Living with HIV, Thailand

\section{Introduction}

The global trend has been to invest in and expand health systems, leading to improved health outcomes across nations [1]. Accordingly, Thailand's Universal Health Coverage (UHC) has made great strides in the last few decades, presently providing coverage for the entire population through its three health insurance programs, the Civil Servant Medical Benefit Scheme (CSMBS), the Social Health Insurance (SHI), and the Universal Coverage Scheme (UCS). The CSMBS provides health insurance to civil servants and pensioners and their dependents, accounting for around 7\% of the Thai population, while the SHI is a government-mandated scheme managed by the Social Security Office to insure privatesector employees (17\% of the Thai population), exclusive of dependents and retirees. The remaining population is covered by the UCS, unconditionally and irrespective of work status [2]. The introduction of UCS in 2002 has arguably contributed the most positive impacts and outcomes to public health in Thailand [3].

One of the biggest contributions UHC has made is towards the fight against HIV/AIDS in Thailand. Since the first reported AIDS case in 1984, HIV/AIDS has been a leading cause of death in Thailand for over two decades. However, in 2019, it was no longer reported in the top ten underlying causes of death [4], dropping from approximately 34,113 deaths in 2000 to 17,215 deaths in 2019 [5]. The successes seen in combatting this disease come from the various rigorous policies adopted by the government since the 1990s, causing Thailand to be heralded as a leader in the prevention and treatment of HIV [6].

It started with surveillance after the first reported case, followed by the early intervention and prevention policies in the 1990s, with one of the most successful programs being the " $100 \%$ condom" program. By the early 2000 s, Thailand had introduced the prevention of mother-to-child transmission (MTCT) program, eliminating MTCT by 2015. Providing universal free ART for all PLHIV since 2006 [7] remains the cornerstone of response to HIV and ensuring that PLHIV receives these medications is paramount [8]. It is part of the World Health Organization (WHO) benchmark of "90-90-90" established by UNAIDS [9], in which $90 \%$ of individuals need to be made aware of their HIV status, $90 \%$ need to have routine and retentive care with consistent ART, and $90 \%$ need to have viral suppression.

The 90-90-90 benchmark serves as a performance assessment for effective intervention by states and how well public health policies are translated into actions. Attaining this standard of care for PLHIV, however, is a long-term fight that needs significant financial support, investment and multisectoral collaborations, particularly from the public sector. As such, this paper aims to investigate 
the association between national HIV/AIDS spending and health outcomes in Thailand between 2008 and 2019. Doing so can provide crucial insights into factors of success in combating this global epidemic.

\section{Methodology}

\subsection{Data Source}

Retrospective longitudinal data of national HIV spending in Thailand over a twelve-year period between 2008 and 2019 was retrieved from the International Health Policy Program, Ministry of Public Health, which maintains the compilation of actual HIV spending by using secondary data from different financing agents particularly public, non-profit and international agents. The spending from households was not compiled due to lack of survey data of patients who voluntary paid out-of-pocket (OOP). Spending is categorized by various activities based on the classification of National AIDS Spending Assessment (NASA) [10] including prevention, care and treatment, orphans and vulnerable children, systems strengthening and program coordination, incentives for human resources, social protection and social services, enabling environment, and research.

HIV-related outcomes in Thailand were extracted from three sources: 1) HIV info HUB, Department of Disease Control which reports the number of PLHIV, total AIDS-related deaths and the MTCT rate, 2) the World Bank which publishes prevalence and incidence of HIV, and 3) the National Health Security Office which maintains the data of AIDS national registration records including the number of people on ART and the registration covers PLHIV who are members of all three public health insurance schemes.

To compare results with other countries having the same upper-middle-income country (UMIC) status, data regarding HIV spending, particularly in prevention and treatment, and AIDS-related deaths of UMICs were extracted from UNAIDS. HIV incidence was obtained from the World Bank, while the health spending profiles were gathered from World Health Organization publications.

\subsection{Data Analysis}

This study applied descriptive statistics for HIV spending profiles to assess the change in HIV-related outcomes during the period observed. Univariate regression was employed to relate HIV spending with selected HIV-related outcomes in Thailand. The scatter plots were applied for comparison across selected UMICs.

The analysis was done in four parts. The first is a descriptive analysis of HIV spending trends and outcomes in Thailand. The second section presents the association between domestic spending on HIV/AIDS and health outcomes by using univariate regression on each independent variable, namely, number of PLHIV, AIDS-related deaths, incidence and prevalence of HIV, number of PLHIV on ART, and MTCT rate. 
The third section focuses on the association between domestic spending on HIV, including the three health insurance schemes, and the number of PLHIV receiving ART, which is the second WHO target in ending HIV/AIDS [11]. The other two $90 \%$ targets were not covered by this study as Thailand has already achieved the first target of awareness, whereas the last target regarding $90 \%$ viral suppression had limitations due to incomplete data on testing for viral suppression [12].

The last section examines the different levels of HIV spending and outcomes among UMICs. Nineteen countries where data is available for comparison were selected for the analysis. Descriptive statistics was performed to assess the correlation of two data sets: 1) preventive spending and incidence of HIV, and 2) treatment spending and AIDS-related deaths. Since the AIDS-related deaths in each country estimated by UNAIDS was reported in a range form, the death rate was computed by using the average of minimum and maximum cases divided by the total population in each UMIC.

\section{Results}

\subsection{Total HIV Spending and Key Outcome Indicators}

The trend of HIV spending over a 12-year period in Thailand is shown in Table 1. Despite being approximately 2\% of Current Health Expenditure (CHE) during this period, the total spending on HIV/AIDS increased gradually from \$208 million in 2008 to almost $\$ 300$ million in 2019. Spending per PLHIV rose significantly from $\$ 347.1$ to more than $\$ 600$ in the last year observed. Domestic sources particularly government spending became the dominant source, increasing from $85.4 \%$ of total HIV/AIDS spending in 2008 to $91.7 \%$ in 2019 . The nation tended to finance curative care and treatment more, which covered almost three quarters (72.4\%) of total HIV expense in 2019, while the spending for preventive care decreased slightly from $21.7 \%$ in 2008 to $14.4 \%$ of total spending in 2019.

Selected HIV-related outcomes spanning the same study period are presented in Figure 1. The number of PLHIV in Thailand declined moderately with a total reduction of 128,063 PLHIV between 2008 and 2019 (Figure 1(a)). However, this decrease was not caused by increase in deaths of PLHIV. In 2019, the number of AIDS-related deaths halved from 26,516 cases in 2008. Incidentally, the number of PLHIV on ART almost quadrupled from 113,530 to 411,391 cases in 2008 and 2019 respectively.

Figure 1(b) illustrates the sharp decrease in HIV incidence from 0.3 to 0.1 per 1,000 uninfected individuals between 2008 and 2019. Despite some fluctuations, the prevalence of HIV gradually dropped from $1.5 \%$ to $1.0 \%$ in the population aged 15 - 49 by 2019. The progress in combating HIV is also shown in the significant decrease of MTCT rates particularly after the year 2009. The MTCT rate was less than $2 \%$ in 2015, reaching the benchmark in containing vertical transmission of HIV set by the World Health Organization [14] (Figure 1(c)). 


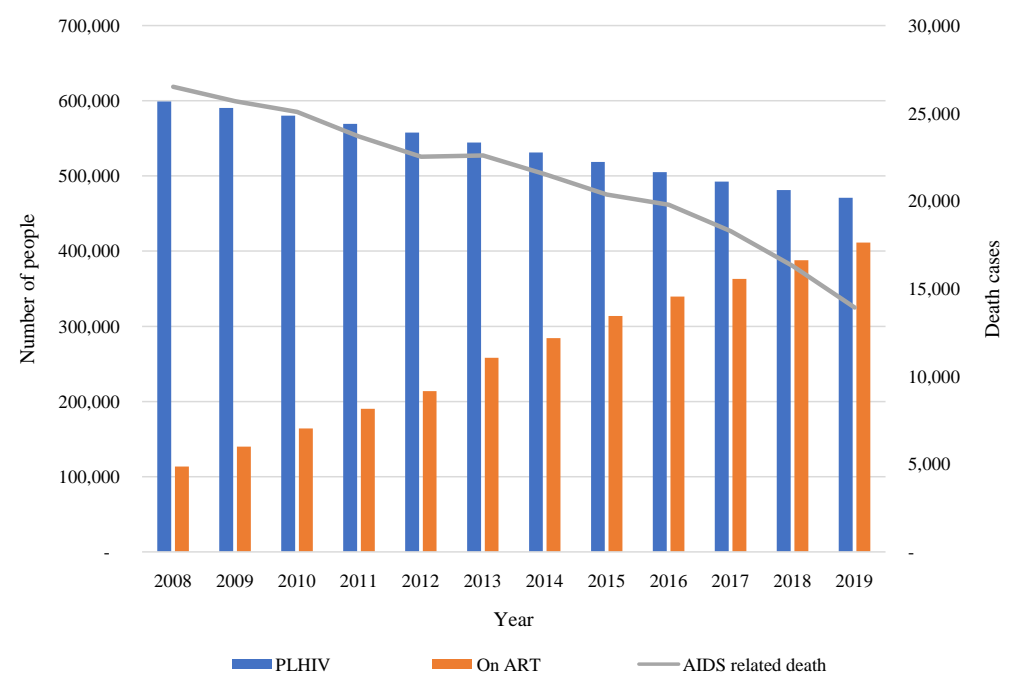

(a)

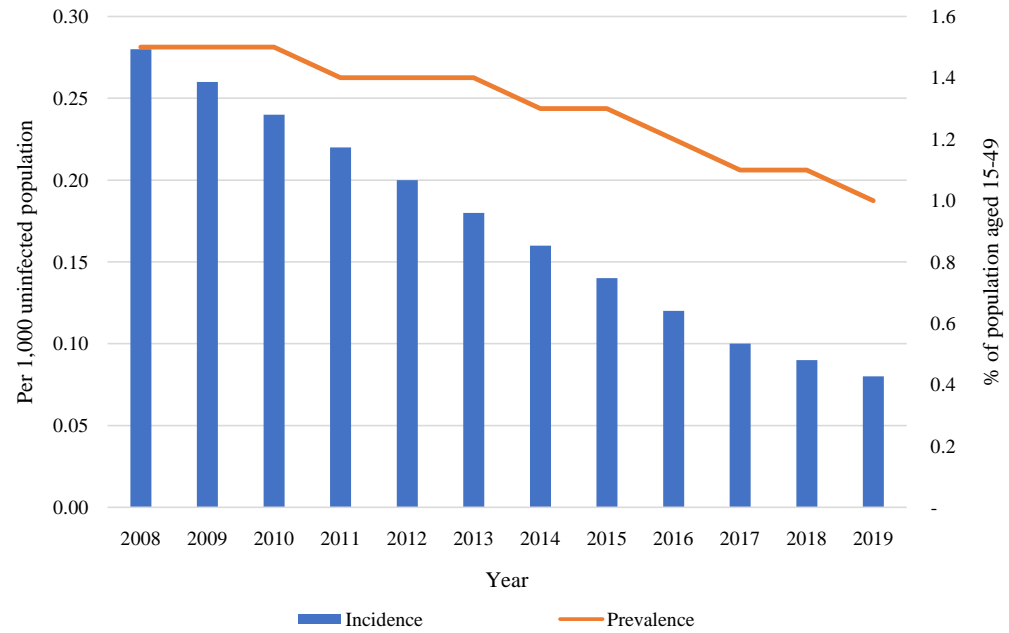

(b)

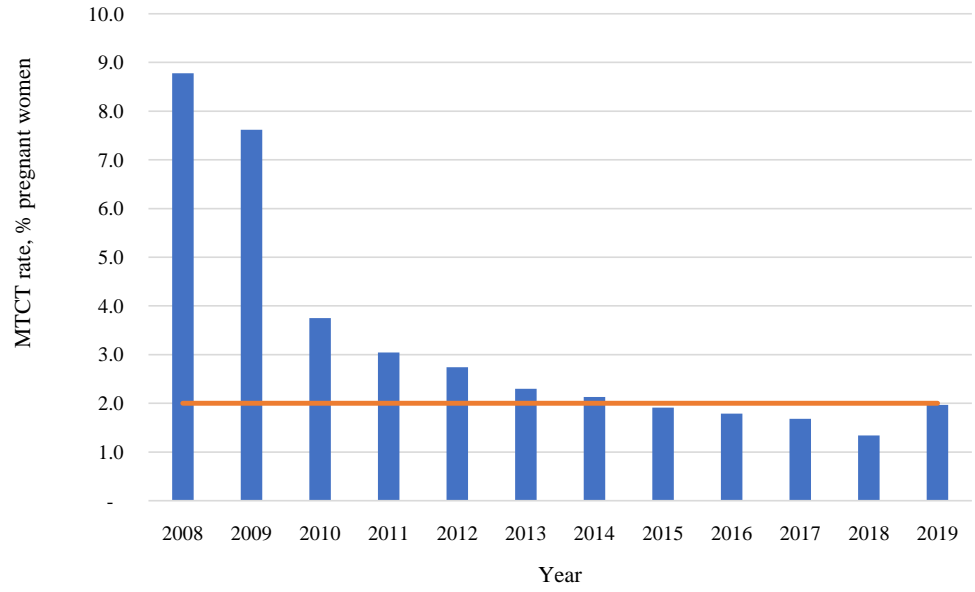

(c)

Figure 1. (a) PLHIV, PLHIV on ART, and HIV-related deaths, 2008-2019. (b) Incidence of HIV and prevalence of PLHIV, 2008-2019. (c) MTCT rates as a percentage of pregnant women, 2008-2019. Note: PLHIV = People living with $\mathrm{HIV}, \mathrm{CHE}=$ Current Health Expenditure. 
Table 1. HIV/AIDS spending profile in Thailand, 2008-2019.

\begin{tabular}{|c|c|c|c|c|c|c|c|}
\hline Year & $\begin{array}{c}\text { HIV/AIDS } \\
\text { spending } \\
\text { (millions USD) }\end{array}$ & $\begin{array}{l}\text { HIV/AIDS } \\
\text { spending per } \\
\text { PLHIV (USD) }\end{array}$ & $\begin{array}{l}\text { Domestic spending } \\
\text { for HIV/AIDS } \\
\text { as } \% \text { of HIV/AIDS } \\
\text { spending }\end{array}$ & $\begin{array}{l}\text { International spending } \\
\text { for HIV/AIDS as } \% \text { of } \\
\text { HIV/AIDS spending }\end{array}$ & $\begin{array}{l}\text { Curative care and } \\
\text { treatment as \% of HIV/ } \\
\text { AIDS spending }\end{array}$ & $\begin{array}{c}\text { Prevention as } \% \\
\text { of HIV/AIDS } \\
\text { spending }\end{array}$ & $\begin{array}{c}\text { HIV/AIDS } \\
\text { spending as \% } \\
\text { of CHE }\end{array}$ \\
\hline 2008 & 208.0 & 347.1 & 85.4 & 14.6 & 65.8 & 21.7 & 2.1 \\
\hline 2009 & 210.2 & 356.0 & 93.3 & 6.7 & 76.1 & 13.7 & 2.1 \\
\hline 2010 & 244.1 & 420.7 & 85.2 & 14.8 & 73.4 & 13.1 & 2.1 \\
\hline 2011 & 325.4 & 571.7 & 85.7 & 14.3 & 73.2 & 13.4 & 2.5 \\
\hline 2012 & 282.9 & 507.4 & 89.8 & 10.2 & 70.2 & 16.7 & 2.0 \\
\hline 2013 & 287.3 & 527.8 & 89.4 & 10.6 & 67.5 & 17.1 & 2.0 \\
\hline 2014 & 268.2 & 504.7 & 85.2 & 14.8 & 64.6 & 17.4 & 1.8 \\
\hline 2015 & 240.8 & 464.5 & 89.4 & 10.6 & 66.9 & 17.3 & 1.6 \\
\hline 2016 & 224.2 & 443.8 & 89.7 & 10.3 & 68.0 & 15.5 & 1.4 \\
\hline 2017 & 248.6 & 504.7 & 89.4 & 10.6 & 70.5 & 14.9 & $1.5^{\mathrm{a}}$ \\
\hline 2018 & 250.7 & 521.1 & 88.8 & 11.2 & 67.3 & 16.4 & $1.4^{\mathrm{a}}$ \\
\hline 2019 & 298.5 & 633.7 & 91.7 & 8.3 & 72.4 & 14.4 & $1.5^{\mathrm{a}}$ \\
\hline
\end{tabular}

a. CHE 2017-2019 is projected data based on 2008-2016, Data source: International Health Policy Program [13]. Note: PLHIV = People living with HIV, $\mathrm{CHE}=$ Current Health Expenditure.

\subsection{Associations between Domestic Spending on HIV and Health Outcomes}

The major source of HIV spending in Thailand is through the domestic budget, prompting an investigation of the association between domestic spending per PLHIV and six HIV health outcomes. Univariate regression analysis displayed that the effect of the domestic spending per PLHIV on all outcomes were statistically significant $(\mathrm{p}<0.05)$. Higher spending was most powerfully associated with decreases in the number of PLHIV, AIDS-related deaths, and marginally associated with reductions in incidence per 1,000 uninfected population, prevalence of HIV infection as a percentage of the population aged 15 - 49, and MTCT rate (Table 2). Greater spending per PLHIV by domestic sources was significantly

Table 2. Univariate regression analysis of domestic spending per PLHIV (USD) and six HIV/AIDS related outcomes.

\begin{tabular}{lclllll}
\hline & $\begin{array}{l}\text { Regression } \\
\text { coefficient }\end{array}$ & SE & P-value Confidence Interval & R-square \\
\hline 1. PLHIV & -395.3377 & 130.431 & $0.013^{*}$ & {$[-685.9561-104.7193]$} & 0.4788 \\
2. AIDS-related death & -38.19584 & 10.26251 & $0.004^{* *}[-61.06214-15.32954]$ & 0.5808 \\
3. Incidence & -0.0006237 & 0.000203 & $0.012^{*}$ & {$[-0.0010765-0.0001709]$} & 0.4850 \\
4. Prevalence & -0.001572 & 0.000516 & $0.012^{*}$ & {$[-0.0027217-0.0004224]$} & 0.4814 \\
5. PLHIV on ART & 1119.864 & 364.7583 & $0.012^{*}$ & {$[307.13181932 .596]$} & 0.4852 \\
6. MTCT rate & -0.0232347 & 0.006778 & $0.006^{* *}[-0.0383369-0.0081325]$ & 0.5403 \\
\hline
\end{tabular}

Note: ${ }^{\star}$ means p-value $\leq 0.05 ;{ }^{* *}$ means p-value $\leq 0.01$ PLHIV $=$ People living with HIV, ART $=$ Antiretroviral therapy, MTCT $=$ Mother-to-child transmission. 
correlated with the increase in people receiving ART, as major spending is on care and treatment including ART, up to $72.4 \%$ in 2019.

\subsection{HIV Spending Profile by Three Health Insurance Schemes}

Most of the domestic HIV spending was covered by the three public health insurance schemes as comprehensive benefit packages by the three schemes cover prevention, health promotion, voluntary counselling and testing, MTCT and ART. Hence, only a small proportion of $5 \%$ to $10 \%$ was financed by the Ministry of Public Health during this period. More than half of the HIV spending by the schemes was invested in ART. The CSMBS spent the highest amount per PLHIV even after a sharp drop from around $\$ 5000$ to $\$ 1604$ after 2013. The expense per PLHIV under SHI was almost $\$ 3000$ in 2008 and notably decreased in the next five years before being fairly steady at around $\$ 400-\$ 700$. The HIV spending per PLHIV under UCS gradually decreased from $\$ 687$ in 2008 to $\$ 353$ in 2019, less than 5 times that of CSMBS. The percentage of PLHIV under CSMBS and SHI who got ART dramatically increased from less than $50 \%$ in 2008 to more than $80 \%$ in 2019, while the percentage of PLHIV receiving ART under UCS was almost 70\% in 2008 with a gradual rise to $90 \%$ in 2019 (Figure 2).

\subsection{HIV Spending and Health Outcomes in UMICs}

To assess the capacity of countries in combating HIV/AIDS, analysis of sources of HIV program financing is one of critical tools. This provides evidences on how much government, external donors and households spend on HIV/AIDS. The variation in health spending across UMICs is shown in Table 3 . The reported health spending in 2018 revealed that most UMICs spent more than 5\% of their Gross Domestic Product (GDP) on health. However, the prioritization of the domestic general government health expenditure (GGHE-d) was less than a fifth of the General Government Expenditure (GGE) except in Costa Rica, 28\%. Also, the GGHE-d as a percentage of CHE was not a significant proportion, with only four countries (Belarus, Botswana, Costa Rica, and Thailand) spending more than 70\% of CHE, and seven dispensing less than 50\%, resulting in high OOP in 2018, most notably Armenia spending 84\% of CHE.

With regards to HIV responses, it is essential to explore how much each UMIC spent on HIV/AIDS and the sources of finance between domestic and international. The country-level total spending on HIV/AIDS varied considerably depending on the size of burden of diseases from HIV/AIDS in each country. Argentina stands out on size of expenditure, almost entirely financed by domestic sources. Domestic sources including public and private spending were the dominant agents in most counties except Jamaica and Venezuela. The amount contributed to HIV/ AIDs from domestic sources ranged from \$627 million in Argentina, to \$274 million and $\$ 199$ million in Thailand and Namibia respectively, to less than $\$ 1$ million in Fiji. Figure 3 illustrates total HIV spending and its sources in the latest data-available year among UMICs. 


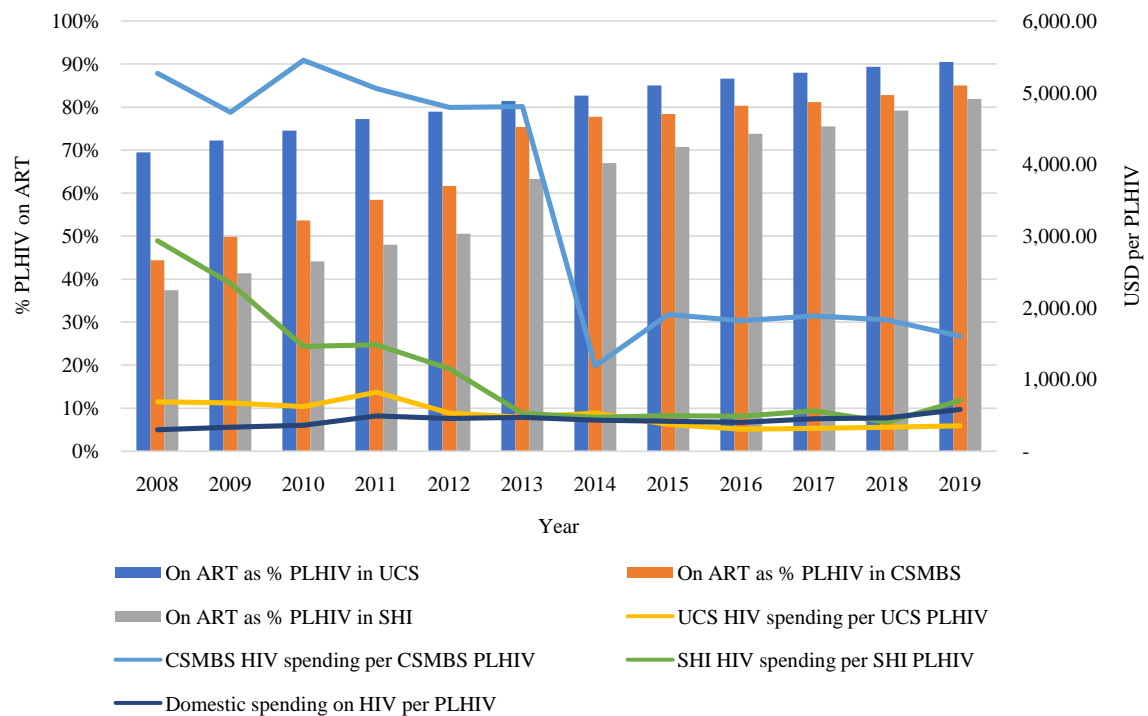

Figure 2. HIV spending per PLHIV and PLHIV on ART among three public health insurance schemes.

Table 3. Health spending profile among selected UMICs in 2018.

\begin{tabular}{|c|c|c|c|c|c|}
\hline Country & $\begin{array}{l}\text { CHE per capita } \\
\text { (USD) }\end{array}$ & $\begin{array}{l}\mathrm{CHE} \text { as } \% \\
\text { GDP }\end{array}$ & $\begin{array}{c}\text { GGHE-D as } \% \\
\text { GGE }\end{array}$ & $\begin{array}{l}\text { GGHE-D } \\
\text { as \% CHE }\end{array}$ & $\begin{array}{l}\text { OOP as \% } \\
\text { CHE }\end{array}$ \\
\hline Median & 356.3 & 5.7 & 10.7 & 57.6 & 33.5 \\
\hline Albania & 274.9 & 5.3 & 9.7 & 54.0 & 44.6 \\
\hline Argentina & 1127.9 & 9.6 & 15.2 & 61.4 & 27.7 \\
\hline Armenia & 422.3 & 10.0 & 5.3 & 12.3 & 84.3 \\
\hline Belarus & 356.3 & 5.6 & 10.6 & 70.4 & 25.0 \\
\hline Botswana & 483.0 & 5.8 & 14.3 & 77.5 & 3.3 \\
\hline Bulgaria & 689.9 & 7.3 & 11.6 & 57.6 & 40.5 \\
\hline Costa Rica & 909.7 & 7.6 & 27.8 & 72.4 & 22.4 \\
\hline Dominican Republic & 461.5 & 5.7 & 15.4 & 44.3 & 44.7 \\
\hline Ecuador & 516.2 & 8.1 & 11.4 & 52.0 & 39.8 \\
\hline Fiji & 214.6 & 3.4 & 7.2 & 68.3 & 14.2 \\
\hline Gabon & 218.4 & 2.7 & 9.4 & 58.6 & 23.1 \\
\hline Georgia & 312.7 & 7.1 & 10.3 & 39.5 & 47.7 \\
\hline Guatemala & 259.6 & 5.7 & 16.7 & 36.0 & 57.5 \\
\hline Jamaica & 321.0 & 6.1 & 13.0 & 64.9 & 17.1 \\
\hline Kazakhstan & 275.9 & 2.9 & 9.1 & 60.8 & 33.5 \\
\hline Malaysia & 427.2 & 3.8 & 8.5 & 51.2 & 35.1 \\
\hline Namibia & 471.5 & 8.0 & 10.7 & 46.1 & 8.4 \\
\hline Thailand & 275.9 & 3.8 & 15.0 & 76.3 & 11.0 \\
\hline $\begin{array}{c}\text { Venezuela } \\
\text { (Bolivarian Republic of) }\end{array}$ & 256.9 & 3.6 & 3.7 & 47.8 & 38.2 \\
\hline
\end{tabular}

Note: Only UMICs which have adequate data on HIV spending and HIV outcomes are included in this table. Bold figure means significant results. CHE $=$ Current Health Expenditure, GGHE-D = Domestic General Government Health Expenditure; GGE $=$ General Government Expenditure, OOP $=$ Out-of-pocket payment, GDP $=$ Gross Domestic Product. 


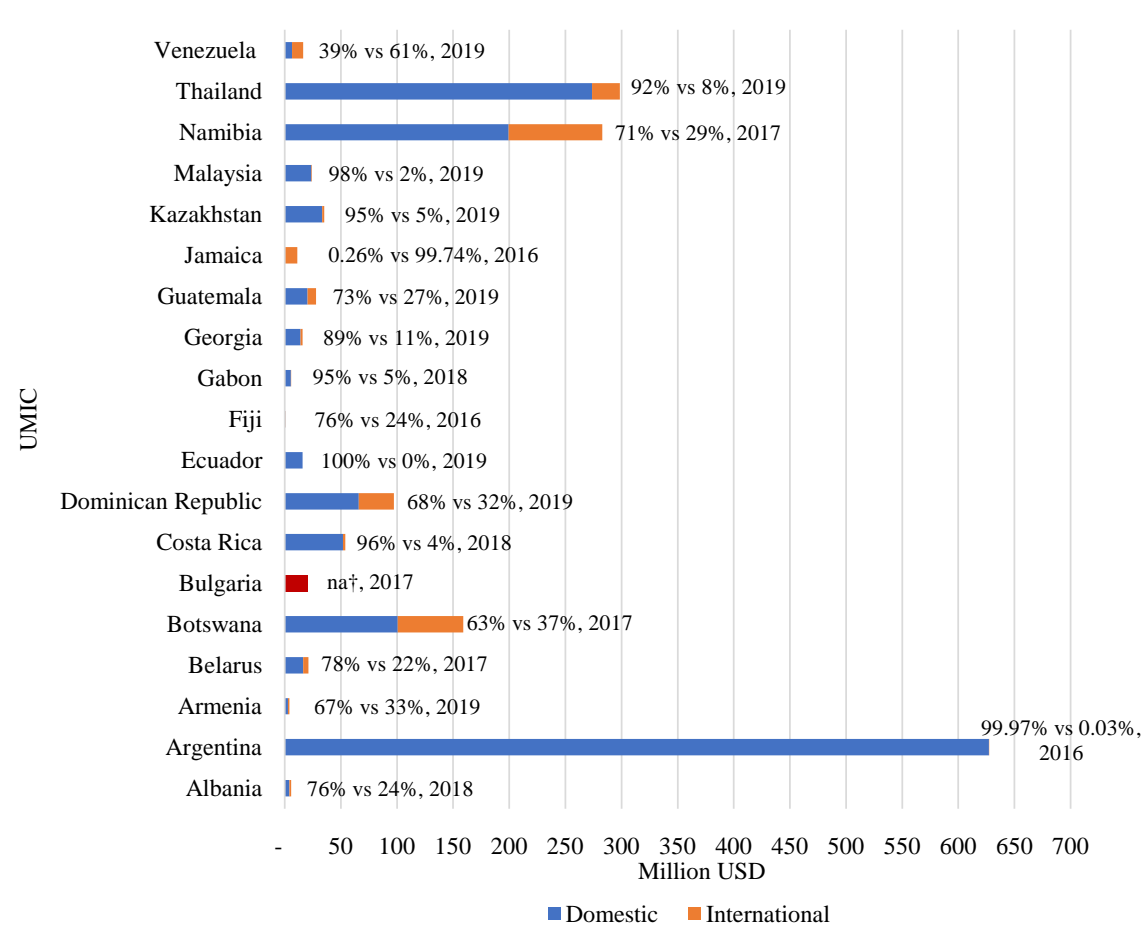

Figure 3. Total HIV spending in each UMIC by source of finance, the latest available year. $\uparrow$ The HIV data from Bulgaria cannot be disaggregated by source of funding.

Two explicit HIV-related outcomes related to spending on HIV prevention and treatment programs, HIV incidence and HIV/AIDS-related mortality, were selected for analysis. UMICs in the scatter plot in Figure 4 are grouped into four quadrants using average intercepts of HIV incidence and prevention spending per PLHIV.

Eight UMICs belong to left lower quadrant with relatively low incidence and relatively low spending on prevention per PLHIV. The burden of new infections varies substantially across UMICs. Generally, countries with high prevention spending per PLHIV seem to have lower HIV incidence (right lower quadrant). However, the incidence of HIV in some countries such as Venezuela, Ecuador Paraguay and Malaysia were low despite relatively low prevention spending per PLHIV, as a result of low pre-existing HIV burden.

The variation across countries on the relationship between HIV treatment spending and AIDS-related death rates per 100,000 individuals is demonstrated in Figure 5. Many countries belong to the lower left quadrant (low spending on ART and low AIDS-related mortality) including Thailand, performing well in terms of relatively lower AIDS-related deaths with relatively lower average spending of HIV treatment.

Expenditures in different countries have different HIV-related outcomes. Generally, higher spending for HIV prevention and treatment programs could be expected to have preferable outcomes, but the coverage of intervention to the key populations (KPs), adherence of citizens to safe sex practice, and access to ART by PLHIV and programmatic efficiency matters. Some countries such as Paraguay, 


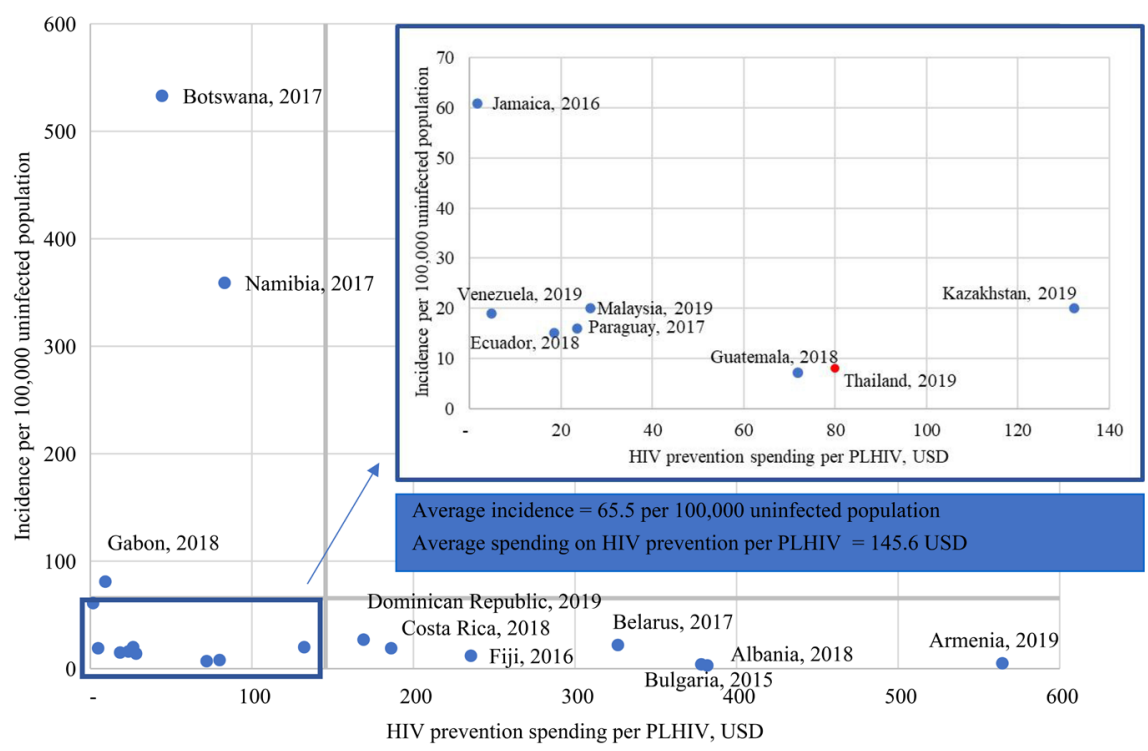

Figure 4. Stages of UMICs on HIV spending on prevention per PLHIV and incidence of HIV, the latest available year.

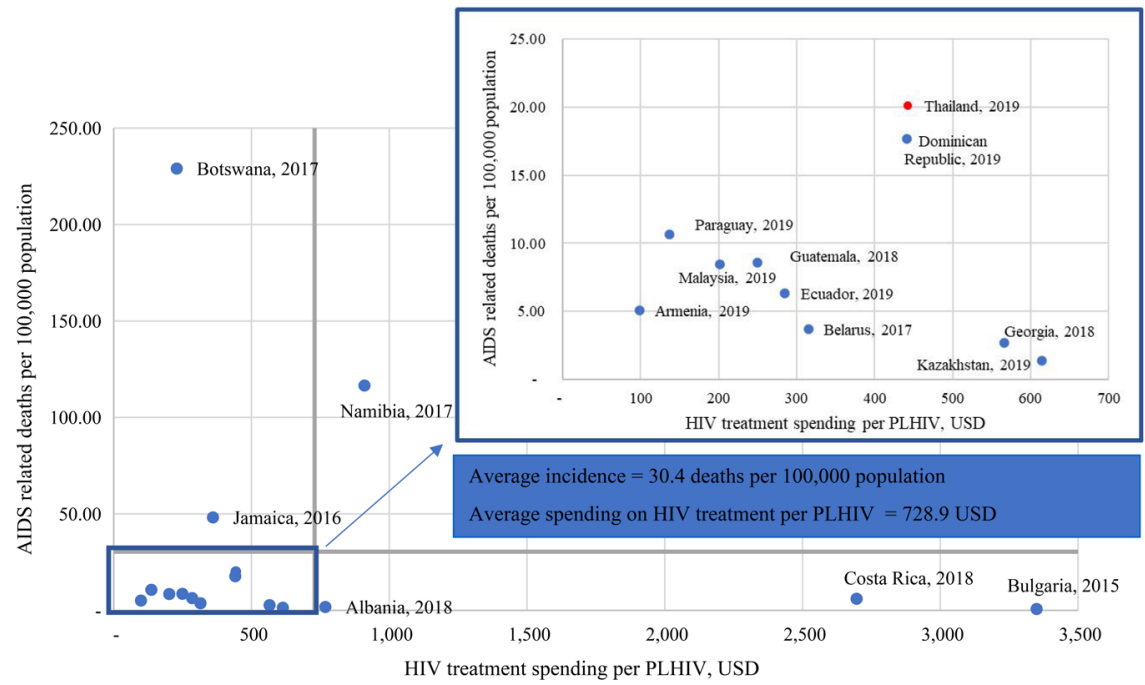

Figure 5. Stages of UMICs on HIV spending on treatment per PLHIV and AIDS-related death, the latest available year.

Malaysia, Ecuador, Guatemala, Thailand, and Kazakhstan had lower average spending of prevention and treatment on HIV/AIDS but still resulted in better-controlled HIV incidence and death rates.

\section{Discussion}

From 2008 to 2019, HIV spending per PLHIV in Thailand increased substantially. The higher expense was associated not only with a decline in the number of PLHIV, prevalence and incidence of HIV and AIDS-related deaths, but also increased coverage of PLHIV receiving ART. The experience from Thailand emphasizes the role of domestic spending on improved HIV-related outcomes and in the long-term 
sustainability of combating HIV/AIDS as has been reported by Dieleman, Joseph L. et al. [15]

When Thailand transitioned from a lower-middle-income country (LMIC) to a UMIC in 2011, it was no longer eligible for Global Fund funding support, though the Global Fund still provides limited support to ART and Tuberculosis (TB) for the migrant population. However, the commitment and fiscal space of the Thai government allowed increased domestic expenditure, with domestic source accounting for $91.7 \%$ of total HIV spending, while donors accounted for $8.3 \%$ in 2019 [10].

The Thai government focused on implementing and then gradually extending ART coverage since the 1990s, and now all essential HIV services are covered and funded domestically [16]. The extension of ART to comply with the "detect and treat" principle enrolls PLHIV at the very early stage of infection with favorable health outcomes [17].

Despite the low risk of consequences from the reduction of international assistance, vigilance is still required to ensure that HIV prevention programs be continually implemented. Global Fund largely supports Civil Society Organizations (CSOs), that play the dominant role in reaching and maintaining trust and connections with KPs such as men who have sex with men, injection-drug users, sex workers, transgender people, and inmates [18]. To achieve the Sustainable Development Goals (SDGs) target 3.3, which aims to end AIDS by 2030 [19], addressing these KPs becomes a crucial strategy as these groups have a higherthan-average incidence of HIV infections [20] and face the most structural barriers on access to government health services [21]. Having more comparative advantage of CSOs, contracting them to provide comprehensive services to KPs should be key policy priorities [22]. As such, CSOs have to turn to the Thai government funding to ensure sustainable long-term management of HIV/AIDS in KPs. However, several limitations such as governance and issues in management systems, operational problems, budget constraints and the rigidity of public financial management [18] have been gradually unfolded. Further improvements for more effective and transparent contracting models are needed for a trustworthy collaboration between the government and non-state actors.

In addition, extending HIV prevention service coverage to some KPs (except pregnant women with have very high coverage of maternal to child prevention program) faces some challenges caused by prevailing stigmatization, while treatment coverage was increased significantly as it has been included in benefit packages of the three public health insurance schemes and with high coverage of ART. A variety of tailored interventions that respond to the different needs of KPs were implemented but the distrust towards accessing formal health services such as HIV testing due to societal discrimination against HIV-infected persons poses a big challenge. The resulting groups of individuals that remain hard-to-reach [23] [24] can be prone to increasing HIV transmission. Therefore, effective management of and investment in HIV prevention programs including health literacy and social supports should be valued by the public health insurance schemes 
and other government institutions in order to end HIV/AIDS.

The analysis amongst UMICs highlights that HIV prevention spending is associated with reduced incidence of HIV, while the pay-off for care and treatment could improve access to ART and lead to decreases in AIDS-related deaths, which aligns with a previous study which indicated that more investment in care and treatment could result in fewer AIDS-related deaths [25]. The results imply that adequate levels of spending per PLHIV could help countries reach the "90-9090 " target in a timely manner.

While having good progress in HIV-related outcomes, Thailand still faces challenges in efficient spending on HIV/AIDS. Only the UCS achieved the second 90 target, despite the other two public health insurance schemes spending more per PLHIV. The reason for this discrepancy is the different payment methods among the three schemes. The UCS has a specific annual budget envelope for HIV/AID, applying a fixed fee schedule for HIV services [26]. The SHI also pays for outpatients and inpatients by using a single capitation rate and pay on top using $\mathrm{Di}$ agnosis-Related Groups (DRGs) for inpatients with a relative weight higher than two [27]. Spending per PLHIV under the CSMBS in 2019 was five times higher than the UCS; as a result of fee-for-service for outpatients [27]. Reforming CSMBS payment methods could contribute to efficient HIV spending.

Sufficient financing alone is not enough to fight against HIV/AIDS. Achieving the UNAIDS target of 90-90-90 requires improvement in five other building blocks of health systems, including access to essential medicines, service delivery, health workforce, health information systems and leadership/governance [28]. These components have all synergistically contributed to how the nation applied several best practices to deal with HIV/AIDS, until it no longer became a top ten cause of mortality in Thailand. Since the introduction of Universal Health Coverage in 2002, the entire Thai population has been covered by public health insurances [29], but ART was not included in the UCS benefits package at its launch in 2002 due to the high cost of medicines and no local production capacity of combined antiretrovirals (ARVs) [30]. Access to medicine for HIV patients was improved when the universal ART program was implemented in 2006 [7] with the capacity of the Thai Government Pharmaceutical Organization (GPO) to produce generic ARVs [31]. The free and universal ART program for all PLHIV has arguably been one of the biggest contributors to preventing HIV/AIDS-related death in the past two decades, averting between 31,000 and 55,000 deaths per year between 2001-2014 [6].

Also, HIV services were scaled up nationally when ART prescriptions were extended to district hospitals instead of being limited to provincial hospitals and large private hospitals [7]. The electronic ART registry-the National AIDS Program (NAP), facilitates replenishment of medication anywhere in Thailand. It accommodates the frequent movement for jobs among key populations. This set up is a crucial factor for improved access. A solid foundation in Thai health services including the full coverage of district hospitals and health centers in all districts and sub-districts has been achieved in the 1990s and 2000s respectively 
[3], while the distribution of health workforce was developed at the same time to support the functions of the district health system [3].

NAP covers HIV patients of all three public health insurance schemes including migrant workers [32], and records information about lab tests, CD4 counts, viral load and emergence of viral resistance, medication and mortality outcome. Currently, the program covers more than $90 \%$ of PLHIV [33].

Overall, the Thai government has demonstrated huge leadership in addressing HIV/AIDS since the peak of the epidemic in the 1990s [21] [34]. Thailand became the first country in Asia to reduce MTCT rate to under 2\%, the target set by the World Health Organization in 2015 [14]. The commitment of the government is also seen with the increase in HIV spending over time, particularly on ART and an annual budget support to CSOs for working with KPs [18].

The findings of this study are subject to some limitations. First, the data was analyzed based on observational historical data. The results provide association between spending and health outcomes, though it cannot claim causal relationships. Second, the association between HIV spending and health outcomes was conducted for only the latest available year in UMICs. Studying the outcome changes over a longer period could be helpful to assess the change of policies implemented during such periods. Also, the relationship between HIV spending and outcomes in each UMIC was compared with a current value of money without adjustment for purchasing power parity. Third, the input data such as the number of PLHIV and AIDS-related death was reported as a range, which only allowed for estimation by using the average value of the data. Fourth, household spending on HIV is not available in any national survey. Despite its very small amount, it can result in underestimation of national spending. However, evidence shows that implementing UHC in Thailand resulted in a significant decline in the incidence of catastrophic health spending and impoverishment which accounted for $2.0 \%$ and $0.4 \%$ in 2015 respectively [35]. OOP for HIV/AIDS can be very small and not affect the results of this study. Last, this study analyzed the overall HIV spending and outcomes, but did not assess effects of specific policies such as universal ART on HIV-related outcomes, which future studies should consider doing.

\section{Conclusion}

Thailand has made remarkable progress with a strong commitment to ending the HIV/AIDS epidemic. Increased domestic spending on HIV/AIDS has notably fostered better HIV-related outcomes, including a substantial decrease in HIV incidence and prevalence of PLHIV, MTCT rate and AIDS-related deaths, and increase in access to ART. The experience from Thailand highlights the great value of domestic spending not only for HIV prevention programs but also ensuring universal access to HIV services and medicines. Despite these advances in health outcomes, challenges from inefficient HIV spending by CSMBS require major reform. 


\section{Authors' Contributions}

SV, VT and WP designed the research study. SV and SS wrote the first draft of the paper. SV and YW analyzed the data. All authors contributed to approving the final draft of the manuscript.

\section{Acknowledgements}

We thank senior researchers of the International Health Policy Program (IHPP) for their advice and support. We would like to extend our appreciation to the staff of the National Health Security Office, and the Division of AIDS and STIs for supplying data for this study.

\section{Funding}

The authors gratefully acknowledge the funding support from the Thailand Science Research and Innovation (TSRI) under the Senior Research Scholar on Health Policy and System Research [Contract No. RTA6280007].

\section{Conflicts of Interest}

The authors declare no conflicts of interest regarding the publication of this paper.

\section{References}

[1] Nurse, J.S.D., Sigfrid, L.P.Y., McDaid, D.J.Y., et al. (2014) The Case for Investing in Public Health. World Health Organization Regional Office for Europe, Copenhagen. http://apps.who.int/iris/bitstream/handle/10665/170471/Case-Investing-Public-Hea lth.pdf? sequence $=1$ \&isAllowed $=y$

[2] Tangcharoensathien, V., Patcharanarumol, W., Suwanwela, W., Supangul, S., Panichkriangkrai, W., Kosiyaporn, H., et al. (2020) Defining the Benefit Package of Thailand Universal Coverage Scheme: From Pragmatism to Sophistication. International Journal of Health Policy and Management, 9, 133-137.

[3] Tangcharoensathien, V., Witthayapipopsakul, W., Panichkriangkrai, W., Patcharanarumol, W. and Mills, A. (2018) Health Systems Development in Thailand: A Solid Platform for Successful Implementation of Universal Health Coverage. The Lancet, 391, 1205-1223. https://doi.org/10.1016/s0140-6736(18)30198-3

[4] Institute for Health Metrics and Evaluation (2017) Thailand. http://www.healthdata.org/thailand

[5] Institute for Health Metrics and Evaluation (n.d.) Global Burden of Disease (GBD). http://ghdx.healthdata.org/gbd-results-tool

[6] Siraprapasiri, T., Ongwangdee, S., Benjarattanaporn, P., Peerapatanapokin, W. and Sharma, M. (2016) The Impact of Thailand's Public Health Response to the HIV Epidemic 1984-2015: Understanding the Ingredients of Success. Journal of Virus Eradication, 2, 7-14. https://doi.org/10.1016/S2055-6640(20)31093-1

[7] Sirivichayakul, S., Phanuphak, P., Pankam, T., O-Charoen, R., Sutherland, D. and Ruxrungtham, K. (2008) HIV Drug Resistance Transmission Threshold Survey in Bangkok, Thailand. Antiviral Therapy, 13, 109-113.

[8] Dieffenbach, C.W. and Fauci, A.S. (2011) Thirty Years of HIV and AIDS: Future Challenges and Opportunities. Annals of Internal Medicine, 154, 766-771.

https://doi.org/10.7326/0003-4819-154-11-201106070-00345 
[9] Joint United Nations Programme on HIV/AIDS (2014) 90-90-90: An Ambitious Treatment Target to Help End the AIDS Epidemic. Joint United Nations Programme on HIV/AIDS, Geneva, 40 p. https://www.unaids.org/sites/default/files/media asset/90-90-90 en.pdf

[10] Wanwong, Y., Viriyathorn, S. and Vongmongkol, V. (2020) Thailand's National AIDS Spending Assessment (NASA) 2018-2019. International Health Policy Program, Nonthaburi.

[11] Joint United Nations Programme on HIV/AIDS (n.d.) 90-90-90 An Ambitious Treatment Target to Help End The AIDS Epidemic. https://www.unaids.org/en/resources/909090

[12] Patcharanarumol, W., Witthayapipopsakul, W., Saengruang, N., Viriyathorn, S., Wanwong, Y., Rajatanavin, N., et al. (2018) Effective Coverage Phase I Fiscal year 2018. International Health Policy Program, Thailand.

[13] International Health Policy Program (n.d.) National Health Accounts. http://www.ihppthaigov.net/research-program/national-health-accounts-nha/

[14] Thisyakorn, U. (2017) Elimination of Mother-to-Child Transmission of HIV: Lessons Learned from Success in Thailand. Paediatrics and International Child Health, 37, 99-108. https://doi.org/10.1080/20469047.2017.1281873

[15] Dieleman, J.L., Haakenstad, A., Micah, A., Moses, M., Abbafati, C., Acharya, P., et al. (2018) Spending on Health and HIV/AIDS: Domestic Health Spending and Development Assistance in 188 countries, 1995-2015. The Lancet, 391, 1799-1829. https://doi.org/10.1016/S0140-6736(18)30698-6

[16] Joint United Nations Programme on HIV/AIDS (2016) Lessons from Thailand: Integrating HIV Services into National Health Schemes.

https://www.unaids.org/en/resources/presscentre/featurestories/2016/february/2016 $\underline{0201 \text { Thailand }}$

[17] Rutstein, S.E., Ananworanich, J., Fidler, S., Johnson, C., Sanders, E.J., Sued, O., et al. (2017) Clinical and Public Health Implications of Acute and Early HIV Detection and Treatment: A Scoping Review. Journal of the International AIDS Society, 20, 21579. https://doi.org/10.7448/IAS.20.1.21579

[18] Pudpong, N., Patcharanarumol, W., Tangcharoensathien, V., Viriyathorn, S., Kulthanmanusorn, A., Witthayapipopsakul, W., et al. (2019) Effective Contracting Model for HIV Service Delivery in Thailand. International Health Policy Program, Nonthaburi.

[19] United Nations DoEaSA, Sustainable Development. (n.d.) The 17 Goals. https://sdgs.un.org/goals

[20] World Health Organization (2016) Consolidated Guidelines on HIV Prevention, Diagnosis, Treatment and Care for Key Populations. World Health Organization, Geneva.

[21] Patcharanarumol, W., Viriyathorn, S. and Tangcharoensathien, V. (2018) After Weaning-off the Global Fund's Support-Can Thailand's HIV/AIDS Program Survive? Journal of Clinical \& Cellular Immunology, 8, Article No. 497. https://doi.org/10.4172/2155-9899.1000497

[22] Coutinho, A., Roxo, U., Epino, H., Muganzi, A., Dorward, E. and Pick, B. (2012) The Expanding Role of Civil Society in the Global HIV/AIDS Response: What Has the President's Emergency Program for AIDS Relief's role been? Journal of Acquired Immune Deficiency Syndromes, 60, S152-S157. https://doi.org/10.1097/QAI.0b013e31825d0383

[23] National AIDS Management Center, Bureau of AIDS TB, and STIs (2017) Thailand AIDS Response Progress Report. Department of Disease Control, Ministry of Public 
Health, Nonthaburi.

[24] National AIDS Committee (n.d.) Thailand National Strategy to End AIDS 2017-2030. https://hivhub.ddc.moph.go.th/Download/Strategy/EN 3Thailand\%20National\%20 Strategy\%20to\%20End\%20AIDS.pdf

[25] Granich, R., Gupta, S., Montaner, J., Williams, B. and Zuniga, J.M. (2016) Pattern, Determinants, and Impact of HIV Spending on Care and Treatment in 38 High-Burden Low- and Middle-Income Countries. Journal of the International Association of Providers of AIDS Care, 15, 91-100. https://doi.org/10.1177\%2F2325957415623261

[26] National Health Security Office (2020) Manual for Fund Management of National Health Security Office 2021. National Health Security Office, Bangkok.

[27] Tangcharoensathien, V., Patcharanarumol, W., Greetong, T., Suwanwela, W., Kesthom, N., Viriyathorn, S., et al. (2019) Thailand Universal Coverage Scheme. World Health Organization, Organization for Economic Co-Operation and Development, Geneva.

[28] World Health Organization (2010) Monitoring the Building Blocks of Health Systems: A Handbook of Indicators and Their Measurement Strategies. World Health Organization, Geneva.

[29] Tangcharoensathien, V., Patcharanarumol, W., Kulthanmanusorn, A., Saengruang, N. and Kosiyaporn, H. (2019) The Political Economy of UHC Reform in Thailand: Lessons for Low- and Middle-Income Countries. Health Systems \& Reform, 5, 195208. https://doi.org/10.1080/23288604.2019.1630595

[30] Ford, N., Wilson, D., Cawthorne, P., Kumphitak, A., Kasi-Sedapan, S., Kaetkaew, S., et al. (2009) Challenge and Co-Operation: Civil Society Activism for Access to HIV Treatment in Thailand. Tropical Medicine \& International Health, 14, 258-266. https://doi.org/10.1111/j.1365-3156.2009.02218.x

[31] Siraprapasiri, T., Srismith, R., Bhakeecheep, S., Ningsanond, P., Poosam-ang, A., Rekakanakul, R., et al. (2013) The Journey of Universal Access to Antiretroviral Treatment in Thailand. United Nations Development Programme, Thailand.

[32] Ingun, P., Narkpaichit, C., Laowahutanon, T., Rekakanakul, R., Pusamang, A. and Kesthom, K. (2015) Integrated National Health Information System of HIV/AIDS in Thailand: Case of NAP Application. National Health Information System of HIV/AIDS, 131-136.

[33] National Health Security Office (2017) 90-90-90 Treatment Target: Thailand Treatment Cascade (PLHIV Registered Under Government Insurances). http://napdl.nhso.go.th/NAPWebReport/LoginServlet

[34] Patcharanarumol, W., Thammatacharee, N., Kittidilokkul, S., Topothai, T., Thaichinda, C., Suphanchaimat, R., et al. (2013) Thailand's HIV/AIDS Program after Weaning-off the Global Fund's Support. BMC Public Health, 13, Article No. 1008. https://doi.org/10.1186/1471-2458-13-1008

[35] Tangcharoensathien, V., Tisayaticom, K., Suphanchaimat, R., Vongmongkol, V., Viriyathorn, S. and Limwattananon, S. (2020) Financial Risk Protection of Thailand's Universal Health Coverage: Results from Series of National Household Surveys between 1996 and 2015. International Journal for Equity in Health, 19, Article No. 163. https://doi.org/10.1186/s12939-020-01273-6 